have more knowledge and more interest in the end. Many curriculum projects and programs are readily absorbed by the best teachers and students. The real challenge is to reach all teachers and all students, not just science specialists.

In an effort to address these needs, the Astronomical Society of the Pacific is organizing a major symposium on North American astronomy education in June 1995. The proceedings of this symposium are to be published in the ASP Conference Series sometime in 1996.

Brown, R.A. 1990. "An Education Initiative in Astronomy", Space Telescope Science Institute.

Sadler, P.M. and Luzader, W.M. 1990. In The Teaching of Astronomy, ed. Pasachoff and Percy, Cambridge UP.

Wentzel, D.G. 1990. In The Teaching of Astronomy, ed. Pasachoff and Percy, Cambridge UP.

\title{
NEW TRENDS IN SCIENCE MUSEUMS
}

Julieta Fierro

Instituto de Astronomia, UNAM, Apartado Postal 70-264, C.P. 04510 D.F., Mexico

E-mail: julieta@astroscu.unam.mx

\section{INTRODUCTION}

An effective way to teach astronomy in an informal manner is by way of popularization. Since the general public is heterogeneous, one must use as many resources as possible to reach a large amount of people. The common ways of popularization are: public lectures, planetarium shows, books, articles, television and radio programs, telescope viewing and one that might encompass all the rest if enough resources are available: a large astronomy hall in a museum or a science center.

Each way of popularization has its advantages. Public lectures give a chance to be in contact with the speaker, to ask questions and understand certain complex problems. Planetaria can give lots of shows and cover the basic educational needs of small communities. Unfortunately, not all developing countries own enough planetaria.

Publications, if well distributed, can reach a large number of people, can be saved, reread, etc. Not all developing countries have regular astronomy articles available to the general population nor astronomy books in native tongues. Libraries and bookstores are scarce; for instance, in Mexico there are a total of 300 bookstores for a population of 82 million people.

Mass media are of course an excellent way to reach a large public. In many developing countries there are no spaces dedicated to science in newspapers, radio and television programs; it is not considered part of culture.

Halls dedicated to astronomy can encompass part of the previous tools plus have 
hands-on exhibits. Large science centers have auditoria where not only public lectures can be given but also other performances like plays and live experiments.

\section{PRACTICAL ADVICE}

2.1 Planetaria. Now small planetaria are available that can fit in relatively small places. If a science center owns one it can easily take it to schools and public places through such projects as "travelling museums" first invented by Canadians. This kind of project is especially advisable for developing countries where the purchase of a large planetarium is out of the question.

2.2 The Travelling Museum. Several science centers have exhibits that are mounted on trucks that can be transported to places outside main population centers. This kind of exhibit is very convenient because it can be housed in schools or public buildings; it can serve a small community and then move on at a relative low expense. The problem is the equipment has to be sturdy and not very heavy or clumsy. The advantages of such exhibits are especially important when one considers deprived communities where transportation for school children is nonexistent. In Mexico we have such an exhibit on the Sun-Earth-Moon system, featuring seasons, eclipses, internal structure.

2.3 The Setting. New museums not only have hands-on exhibits, on occasions they have abandoned square bare rooms and have created scenographic settings with illumination, odor and sounds that appeal to all senses (Fierro and Doddoli, 1993).

2.4 Labels. Reading labels is still a major problem. Even though research has demonstrated that short labels with different levels of explanation, using different sizes and color coding are better understood, most visitors do not read them. Many children jump from one exhibit to the next and do not have enough patience to complete the experiment the scientist that proposed it had in mind. Some museums carry labels for blind visitors, at least for a few exhibits.

2.5 Maintenance. Maintenance is the major problem in Mexican museums, especially for those that do not have private sponsorship (Fierro, 1994).

2.6 Ushers. Ushers are becoming more important every day for science centers and museums. Person to person relationships are extremely rewarding. On floor exhibits, guided tours and question answering make the visit to museums a more fruitful learning experience, especially for people with no background in science.

Ushers have to be selected carefully so that they like to be with people, and are not afraid to admit there are things they do not understand. Computer links with data bases are especially useful so they can get the information they require.

2.7 Activities. One of the most rewarding experiences for youngsters at a science center is the participation in the elaboration of objects. Manipulation is especially important, and taking home something hand-made. For instance, astronomy activities can consist of building sundials, alka-seltzer rockets, extraterrestrial beings from scratch, or three dimensional constellations.

The French group has developed particularly attractive and interesting activities for large age groups and people with different backgrounds. (See references in Pasachoff and Percy, 1990). 
2.8 Outdoor Activities. Outdoor activities offer a great variety of opportunities. For instance, paths are made through gardens featuring animals in their natural habitat as well as plants, cultivation and farming, etc. Outdoor activities for small children involving physical activity and water experiments are especially suited for large outdoor spaces.

2.9 Computers. Presently not only are computers part of exhibits at the museum halls, they are servicing the libraries where Internet links provide information on museums all over the world.

Little by little, more museums use computers for curator purposes; they share experiences, security problems, and general information with their colleagues all over the world.

2.10 Sponsorship. One of the great success of some museums is their sponsorship ideas. For example, one museum has each apparatus paid and maintained by a private institution (the display has a label with the company's name on it). It also has large companies pay for the monthly entrance of public schools in deprived neighborhoods; the children are taken to the museum, receive propaganda from the company, visit the museum and Imax show, are given lunch and are taken back to their school. Such a system guarantees complete booking of the Museum, one million visitors in eight months, and sufficient budget to keep the facilities in prime condition.

2.11 Shops. Shops, bookstores, libraries, video services, on-line-computers are a very important part of museums. One must take advantage of the great interest a visit to a scientific exhibit arouses to provide more information so it must be handy for the visitors to continue and reinforce their interests (Fierro, 1992).

\section{VERY SMALL MUSEUMS}

3.1 The Ensenada Museum. A group of enthusiastic teachers has created a science museum with extremely few resources and with great success in the northern town of Ensenada in Mexico. For instance, they retrieved an outcast fishing boat and hauled it to a public park and installed in it a "Noah's Ark" where visitors can learn about ecology.

The people at the Ensenada Museum are particularly active; with their outreach programs, they have visited such poor areas that they have even taught the people how to build latrines.

3.2 The Oaxaca Experience. A group of Mexican anthropologists is opening a museum in one of the poorest zones of the country. Their purpose is to use the museum as an aid for school. They really do not care too much about the exhibits but on the skills children will acquire while they visit it.

In other words they feel this museum should be more formative than informative. This place is completely bilingual; many children only speak zapotec language, so all labels have to be in two languages. The museum includes dormitories, so students from distant communities can spend the night at the installations. They can accommodate 30 live-in visitors at a time. Many of the displays are adaptations from what has been set up in other places. 


\section{THE FUTURE}

Probably computer links will have a major influence on all museums in the near future. Links already exist between all major centers. They exchange expertise of all sorts: security, curator experiences and images and labels of many exhibits. Several museums would benefit from the participation of professional astronomers in their design, updating and elaboration of didactic material.

Fierro, J. 1992, Teaching of Astronomy in Asian-Pacific Region, Bull. 5, Ed. Isobe Y., p. 25.

Fierro, J. and Doddoli, C. 1993, Museum News, p. 35.

Fierro, J. 1994, Teaching of Astronomy in Asian-Pacific Region, Bull. 6, Ed. Isobe Y., p. 1.

Pasachoff, J.M. and Percy, J.R. Ed. 1990, The Teaching of Astronomy, IAU Colloquium 105.

\section{THE ROLE OF AMATEURS}

Syuzo Isobe

National Astronomical Observatory, Mitaka, Tokyo 181, Japan

E-mail: oisobex@c1.mtk.nao.ac.jp

1. How to Popularize Astronomy. There are different ways to popularize astronomy. In recent years, professional astronomers have written many popular astronomy books, but only a small fraction of people, that is, less than $1 \%$ of the total population try to read them. Probably three of the most efficient ways are 1) school education, 2) social education, and 3 ) contributions of amateurs.

All people pass through a school period when some parts of astronomy are taught to school pupils. This is a great opportunity for the people to study astronomy. However, in Japan a large fraction of teachers, especially in elementary schools, did not take astronomy courses at university and therefore they cannot make their lectures attractive for school pupils. Although many pupils at the 1st or 2 nd grade of elementary schools are interested in black holes, star formation, and so on, their interest disappears after unattractive lectures. There are some efforts to escape from these difficulties, but it takes long years.

In the 1970's, many planetariums were built and those number over 400 in Japan (Isobe 1991). Then, in the period from 1984 to the present, many public observatories having a telescope with an aperture larger than $50 \mathrm{~cm}$ have been built (Isobe 1994) and those number over 50 and still increasing. This is a fortunate situation to popularize astronomy. However, nearly all the local governments who built those facilities employ only one or a few staff members who have not enough astronomical knowledge. Therefore, their activities strongly rely on the assistance of amateur 